\title{
Anti-diabetic drug utilization of pregnant diabetic women in us managed care
}

\author{
Caitlin A Knox ${ }^{1 *}$, Joseph AC Delaney ${ }^{2}$ and Almut G Winterstein ${ }^{1,3}$
}

\begin{abstract}
Background: With the increasing prevalence of type 2 diabetes in young adulthood, treatment of diabetes in pregnancy faces new challenges. Anti-diabetic drug utilization patterns of pregnant women with pre-existing diabetes are poorly described. We aim to describe anti-diabetic (AD) agent utilization among diabetic pregnant women.

Methods: We utilized IMS LifeLink, including administrative claims data of patients in US managed care plans, to establish a retrospective cohort of women, age $18-46$ years $(N=96,740)$ with billed procedures for a live birth, and a 12 month eligibility period before and 3 month after delivery. Diabetes mellitus was identified from $\geq 2$ in- or outpatient claims with diagnoses (ICD-9-CM 250.XX) before pregnancy. We estimated the prevalence of AD drugs before, during and after pregnancy, and secular trends across the study period (1999-2009), using linear regression. A sensitivity analysis was conducted to identify the extent of misclassification of trimesters.
\end{abstract}

Results: Almost six percent $(n=5,581)$ of the live birth cohort had diabetes mellitus. Throughout the study, $48 \%$ (1999) and 78\% (2009) $(p<0.0001)$ of diabetic women received AD drugs during pregnancy. The most common AD drugs during pregnancy were insulin, metformin, sulfonylureas, thiazolidinediones (TZD), and combination AD. The annual prevalence of insulin use increased by only 1\% from 39\% (1999) to 40\% (2009) ( $p=0.589)$ during pregnancy, while use of sulfonylureas and metformin increased from 2.5\% and 4.2\% (1999) to $17.3 \%$ and $15.3 \%$ (2009) $(p<0.0001)$, respectively. Insulin and sulfonylurea use steadily increased in prevalence from the 1 st to 3 rd trimester (16.5\% and 3.3\% to 33.0\% and 7.5\%), while metformin and TZD use decreased (11.4\% and $1.6 \%$ to $3.8 \%$ and $0.2 \%$ ).

Conclusions: AD use during pregnancy demonstrates the need for additional investigation regarding safety and efficacy of AD drugs on maternal outcomes.

Keywords: Pharmacoepidemiology, Drug utilization, Pregnancy, Managed care

\section{Background}

Current estimates project that by 2025 one in three adults in the United States (US) will have diabetes mellitus [1]. In 2010, approximately $11 \%$ of US women aged 20 years or older were either diagnosed or had undiagnosed diabetes [1]. This reflects an increase in diabetes prevalence of $2 \%$ in this age group over the last five years, with a corresponding 1.9 million new cases of diabetes diagnosed in 2010 [1]. This growth is almost exclusively attributable to type 2 diabetes mellitus, which traditionally has had its onset in later stages of adulthood [1,2].

\footnotetext{
*Correspondence: cknox@ufl.edu

'Department of Pharmaceutical Outcomes \& Policy, College of Pharmacy, Gainesville, FL, USA

Full list of author information is available at the end of the article
}

The growing prevalence of type 2 diabetes in young adults is particularly important, as more young women will be diagnosed during reproductive years [2]. Poorly controlled diabetes both before and during the first trimester of pregnancy can cause major birth defects, spontaneous abortions, and stillbirths [2]. Despite this well-established fact, more than $60 \%$ of women with pre-existing diabetes have difficulty managing their glycemic control during pregnancy [3-5]. Researchers and providers agree that glycemic control is one of the most important modifiable risk factors in minimizing birth defects of infants born to women with pre-existing diabetes [6-10]. However, little experience and evidence regarding the safety and effectiveness of oral agents during pregnancy exists.

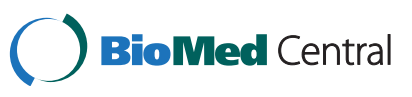


While type 1 diabetes management requires insulin and thus leaves little choice during pregnancy, type 2 diabetes may be managed with life-style modifications, oral antidiabetic agents, and/or insulin. Among oral agents, several new molecular entities have been added within the last ten years with limited data on pregnancy outcomes. Given the limited research that is available on anti-diabetic agent use during pregnancy, we aimed to describe anti-diabetic agent utilization before, during and after pregnancy and determine secular trends among classes of anti-diabetic drugs across the 10-year study period (1999-2009) in women with pre-existing diabetes.

\section{Methods}

We utilized the IMS LifeLink Database, which consists of commercial health plan information from more than 100 managed care plans throughout the US. The majority of the payer type within the database is commercially insured. The IMS LifeLink database also includes Medicaid,
Medicare, self-insured and unknown payer types. The database records are generally representative of the commercially insured population in terms of gender and age. The IMS LifeLink database is comprised of eligibility and demographic information, as well as, inpatient and outpatient claims data with detail on diagnosis and procedures, and prescription drug claims. This database contained a random sample of 6 million women aged 18 to 46 years with no prescription drug claim for contraceptives. To be included in our study cohort we required women to have a billed medical procedures code for live birth (Table 1), and 12 months continuous insurance coverage before and 3 months after delivery. Women were required to have at least one prescription drug claim before pregnancy, to confirm prescription drug coverage. A total of 96,740 women met the inclusion criteria for the cohort.

To identify patients with pre-existing diabetes, we required two in- or outpatient claims with diagnosis of

Table 1 Delivery-related procedure (CPT-4) codes used to identify live births

\begin{tabular}{|c|c|}
\hline Code & Description \\
\hline 01960 & Anesthesia for vaginal delivery only \\
\hline 01961 & Anesthesia for cesarean delivery only \\
\hline 01962 & Anesthesia for urgent hysterectomy following delivery \\
\hline 01963 & Anesthesia for cesarean hysterectomy w/o any labor analgesia/anesthesia care \\
\hline 01967 & Neuraxial labor analgesia/anesthesia, planned vaginal delivery \\
\hline 01968 & Anesthesia for cesarean delivery following neuraxial labor analgesia/anesthesia \\
\hline 01969 & Anesthesia for cesarean hysterectomy following neuraxial labor analgesia/anesthesia \\
\hline 59050 & Fetal monitoring in labor, physician w/written report \\
\hline 59051 & Fetal monitoring in labor, physician w/written report; interpretation only \\
\hline 59400 & Routine obstetric care, antepartum care, vaginal delivery, \& postpartum care \\
\hline 59409 & Vaginal delivery only (w/wo episiotomy \&/or forceps) \\
\hline 59410 & Vaginal delivery only (w/wo episiotomy \&/or forceps); w/postpartum care \\
\hline 59412 & External cephalic version, w/wo tocolysis \\
\hline 59414 & Delivery, placenta (separate procedure) \\
\hline 59430 & Postpartum care only (separate procedure) \\
\hline 59510 & Routine obstetric care w/antepartum care, cesarean delivery, \& postpartum care \\
\hline 59514 & Cesarean delivery only \\
\hline 59515 & Cesarean delivery only; w/postpartum care \\
\hline 59525 & Subtotal/total hysterectomy after cesarean delivery \\
\hline 59610 & Routine obstetric care, vaginal delivery, w/antepartum, postpartum care, previous c-section \\
\hline 59612 & Vaginal delivery only, previous cesarean delivery \\
\hline 59614 & Vaginal delivery only, previous cesarean delivery; w/postpartum care \\
\hline 59618 & Routine obstetric care, ante/postpartum, cesarean delivery after failed vaginal delivery, previous cesarean delivery \\
\hline 59620 & Cesarean delivery, after failed vaginal delivery, previous cesarean delivery \\
\hline 59622 & Cesarean delivery, after failed vaginal delivery, previous cesarean delivery; w/postpartum care \\
\hline 99436 & Attendance at delivery, at request of delivering physician, \& stabilization of newborn \\
\hline 99440 & Newborn resuscitation \\
\hline
\end{tabular}


diabetes mellitus (International Classification of Diseases, Ninth Revision, Clinical Modification (ICD-9-CM) 250. $\mathrm{XX}$ ) within the 3 months preceding conception $[11,12]$. ICD-9-CM codes identify the specific type of diabetes mellitus by the fifth digit of the code, but previous research suggests that current coding practices do not provide sufficient accuracy to identify the type of diabetes from the fifth digit of the ICD-9-CM code $[13,14]$. Therefore, we did not separate women according to their diabetes mellitus type, but decided to present a subgroup analysis in women with high propensity to have type 2 diabetes [15]. For the analysis, we assumed the presence of type 2 diabetes when $100 \%$ of diabetes mellitus diagnoses in the claims indicated type 2 diabetes (ICD-9-CM $250 . \times 0$ or $250 . \times 2$ ) [15]. The "other diabetes" subgroup included all women with type 1 diabetes mellitus claims and those with mixed or unspecific claims (i.e., missing the 5 th digit).

We defined the delivery date as the date of the first Current Procedural Terminology (CPT-4) claim for live birth for each woman. We included women with live births only because we needed to obtain an estimated conception date for each woman. Inclusion of terminated pregnancies would not have allowed the determination of trimesters because the date of termination relative to conception would be unknown. Since we did not have access to the Last Menstrual Period (LMP) date, it was necessary for us to calculate the conception date of the pregnancy. This was done by subtracting nine months (270 days) from the delivery date $[16,17]$. Each trimester of pregnancy was assigned a 91-day interval $[16,17]$. Pre-pregnancy interval were identified as the three months preceding the imputed conception date to classify the presence of pre-existing diabetes and capture pre-pregnancy drug utilization. We separately defined an after pregnancy interval as the threemonth time period after the delivery date, resulting in five distinct 3-month periods, which were used to define drug use prevalence.

Because we relied on an imputed conception date, there was a potential for misclassification of the pre-pregnancy period and the following trimesters. The risk of misclassification of the pregnancy periods was particularly high in women with diabetes, because they are at higher risk for pre-term births (i.e. shorter gestation periods). In order to evaluate this effect we conducted a sensitivity analysis, where we utilized the first healthcare encounter with a pregnancy code (ICD-9-CM: V22, V23, V72.40, V72.42 and CPT-4:81025) to estimate conception date [18]. Using the first pregnancy claim as the conception date, the mean length of pregnancy for the cohort was 6.55 months with at standard deviation of 1.64 months. Five percent of the diabetes cohort had an ICD-9-CM claim for early delivery (644.2, 644.20, and 644.21). Therefore, we conducted another sensitivity analysis where we adjusted the gestation length to 245 days for women with an early delivery claim [19]. We saw that the drug class utilization in the sensitivity analysis did not differ significantly with the originally imputed pregnancy periods we calculated using 270 days subtracted from the delivery date.

Among the ten anti-diabetic drug classes identified within the IMS pregnancy cohort, we focused our analysis on the five most commonly utilized drug classes before, during and after pregnancy: insulin, biguanides, sulfonylureas, thiazolidinediones, and oral anti-diabetic combinations. The remaining anti-diabetic drug classes all showed prevalence rates of less than 1\% (alpha-glucosidase inhibitors, amylin analogs, dipeptidyl peptidase-4, GLP-1 receptor agonists and meglitinide analogues). All insulin products were collapsed into one category reflecting American Hospital Formulary Service (AHFS) drug class 68.20.08. We calculated respective drug class prevalence as the proportion of diabetic women with a drug claim of a particular class during each of the designated periods.

We estimated the prevalence along with the 95\% confidence intervals of anti-diabetic drug class utilization before, during (for each trimester) and after pregnancy. We investigated the secular trend of annual drug utilization prevalence using linear regression. All analyses were conducted with SAS 9.2, Cary, NC. The University of Florida Institutional Review and Privacy Boards approved this study.

\section{Results}

Over the course of the ten-year study period (1999-2009), we identified 5,581 (5.9\%) women with pre-existing diabetes among all women with a procedure code for live birth. A total of 4,043 women had only ICD-9-CM codes consistent with type 2 diabetes mellitus. Diabetic women were on average slightly older, had more physician visits and more prescription drug claims before pregnancy (Table 2). As expected, diabetic women had a higher prevalence of additional co-morbid conditions than nondiabetic women had, but had similar frequencies of smoking, alcohol and drug abuse. Diabetic women also had a higher prevalence of cesarean section delivery compared to non-diabetic women, with $44.8 \%$ versus $27.2 \%$ respectively. There was a higher prevalence of diabetics in the East region of the US, and a lower prevalence in the South and West. Within the sub-group analysis, type 2 diabetic women had similar baseline characteristics, but the average number of $\mathrm{AD}$ prescriptions before pregnancy was lower in the type 2 diabetes only group when compared to all diabetic women.

The annual mean age for the diabetic pregnancy cohort had a statistically significant increase from 29.85 years to 32.90 years from 1999 to 2009 (beta $=0.34, \mathrm{p}<0.0001$ ). The prevalence of anti-diabetic treatment (insulin or oral anti-diabetic drugs) among diabetic women before 
Table 2 Baseline characteristics of the study cohorts

\begin{tabular}{|c|c|c|c|c|c|}
\hline \multirow[t]{4}{*}{ Variable } & \multirow[t]{4}{*}{ Category } & \multirow{4}{*}{$\begin{array}{c}\mathrm{DM}^{*} \\
\mathrm{~N}=5,581\end{array}$} & \multirow{2}{*}{\multicolumn{2}{|c|}{$\begin{array}{c}\mathrm{DM}^{*} \\
\mathrm{~N}=5,581\end{array}$}} & \multirow{4}{*}{$\begin{array}{l}\text { Not DM* } \\
\mathrm{N}=91,159\end{array}$} \\
\hline & & & & & \\
\hline & & & T2DM* & Other $\mathrm{DM}^{*}$ & \\
\hline & & & $N=4,043$ & $N=1,538$ & \\
\hline \multicolumn{2}{|l|}{ Age: Years (SD) } & $32.3(5.1)$ & $32.5(5.1)$ & $32.1(5.0)$ & $30.1(5.3)$ \\
\hline \multicolumn{2}{|l|}{ Eligibility: Months (SD) } & $56.8(25.2)$ & $57.4(25.2)$ & $55.1(24.9)$ & $51.3(24.4)$ \\
\hline \multicolumn{2}{|l|}{ Physician office visits 3 months before Pregnancy (SD) } & $21.3(24.5)$ & $20.8(25.2)$ & $22.5(22.5)$ & $14.6(17.8)$ \\
\hline \multirow[t]{2}{*}{ Number of Prescription Drug Claims 3 months before Pregnancy (SD) } & Anti-Diabetic & $3.0(7.5)$ & $1.4(4.5)$ & $7.2(11.2)$ & $0.1(0.9)$ \\
\hline & Other & $14.6(18.8)$ & $13.9(18.5)$ & $16.4(19.4)$ & $9.7(12.4)$ \\
\hline \multirow[t]{2}{*}{ Delivery Route } & Vaginal & $55.2 \%$ & $58.8 \%$ & $47.7 \%$ & $72.8 \%$ \\
\hline & Cesarean Section & $44.8 \%$ & $41.2 \%$ & $52.3 \%$ & $27.2 \%$ \\
\hline \multirow[t]{8}{*}{ Comorbid Conditions } & PCOS & $12.5 \%$ & $13.1 \%$ & $10.9 \%$ & $5.5 \%$ \\
\hline & Hypertension & $18.2 \%$ & $17.0 \%$ & $21.4 \%$ & $4.3 \%$ \\
\hline & Infertility & $14.7 \%$ & $15.6 \%$ & $12.2 \%$ & $10.6 \%$ \\
\hline & IVF Claim & $0.1 \%$ & $0.1 \%$ & $0.1 \%$ & $0.0 \%$ \\
\hline & Obesity & $13.9 \%$ & $13.4 \%$ & $15.2 \%$ & $3.8 \%$ \\
\hline & Smoking & $6.0 \%$ & $6.0 \%$ & $5.9 \%$ & $4.6 \%$ \\
\hline & Alcohol & $0.8 \%$ & $0.8 \%$ & $1.0 \%$ & $0.9 \%$ \\
\hline & Drug Abuse & $0.7 \%$ & $0.7 \%$ & $0.6 \%$ & $0.7 \%$ \\
\hline \multirow[t]{4}{*}{ Region } & East & $32.6 \%$ & $33.6 \%$ & $26.6 \%$ & $20.6 \%$ \\
\hline & Midwest & $43.1 \%$ & $43.1 \%$ & $40.6 \%$ & $43.8 \%$ \\
\hline & South & $12.1 \%$ & $11.1 \%$ & $19.7 \%$ & $17.9 \%$ \\
\hline & West & $12.3 \%$ & $12.2 \%$ & $13.2 \%$ & $17.7 \%$ \\
\hline \multicolumn{2}{|l|}{ Conception Year (SD) } & 2005 (2.4) & $2005(2.3)$ & 2005 (2.6) & 2005 (2.6) \\
\hline
\end{tabular}

${ }^{*} \mathrm{DM}=$ pre-existing diabetes mellitus, $\mathrm{T} 2 \mathrm{DM}=$ type 2 diabetes mellitus.

pregnancy increased from $25.9 \%$ (CI: 25.74, 26.06) to 36.1\% (CI: 35.94, 36.26) from 1999 to 2009 (beta $=1.3 \%$, $\mathrm{p}<0.0001$ ) (Figure 1). During pregnancy, we observed a statistically significant rise in anti-diabetic drug treatment from $48.3 \%$ in 1999 to $77.9 \%$ in 2009 (beta $=3.4 \%$, $\mathrm{p}<0.0001$ ). The growth in the prevalence of treatment was similar across trimesters with the largest growth in the third trimester, which saw a $23 \%$ increase in treatment from $36.8 \%$ (CI: 36.58, 37.01) in 1999 to $59.4 \%$ (CI: 59.18, 59.62) in 2009 (beta $=2.4 \%, \mathrm{p}<0.0001$ ). The prevalence of diabetic women who were treated with an anti-diabetic drug after pregnancy approximately doubled from 18.3\% (CI: 18.11, 18.49 ) to $39.7 \%$ (CI: 39.51, 39.89) from 1999 to 2009 at a rate of $1.8 \%$ (CI: 1.14, 2.53) per year (p <0.0001) (Figure 1).

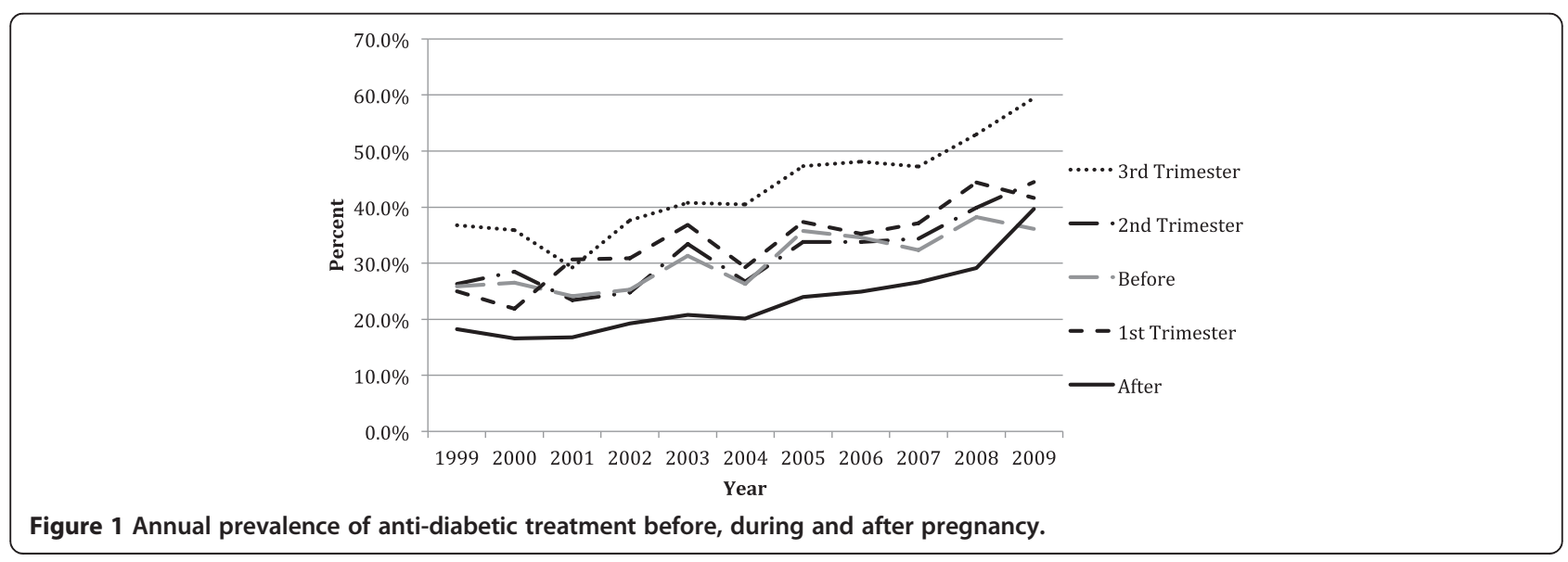


Among the various therapeutic classes, metformin and sulfonylureas showed the greatest increase over the study period from $4.2 \%$ (CI: 4.11, 4.29) and 2.5\% (CI: 2.44, 2.56) in 1999 to $15.3 \%$ (CI: $15.21,15.39$ ) and $17.3 \%$ (CI: 17.26 , 17.36 ) in 2009 , respectively ( $\mathrm{p}<0.0001$ for each drug class) (Figure 2). The sulfonylurea drug class included glimepride, glipizide, and glyburide at $28 \%, 47 \%$ and $25 \%$ respectively. Thiazolidinediones and combination drugs remained constant at $1.6 \%(\mathrm{CI}: 1.56,1.64)$ and $0.5 \%(\mathrm{CI}$ : $0.47,0.53$ ) over the course of the study. As expected rosiglitazone saw a decrease from $50 \%$ to $23.1 \%$ within the thiazolidinesdione drug class (beta $=-3.4, \mathrm{p}=0.12$ ). Insulin use during pregnancy increased $1 \%$ over the 10 -year period from $39 \%$ (CI: 38.81, 39.19) in 1999 to $40 \%$ (CI: $39.81,40.19$ ) in 2009 (p-value $=0.589$ (Figure 2).

When pooled across the entire study period, the prevalence of metformin use before pregnancy in all diabetic women was $13.7 \%$ (CI: 13.11, 14.28), which decreased to $12.3 \%$ (CI: $12.21,12.39$ ) during pregnancy and then decreased further after pregnancy to $7.7 \%(\mathrm{CI}$ : $7.62,7.78$ ) (Figure 3). Insulin utilization behaved as expected, with a lower average prevalence before pregnancy of $10.7 \%$ (CI: 10.52, 10.88), which more than tripled to $35.3 \%$ (CI: 35.11, 35.48) during pregnancy and then dropped again to $11.8 \%$ (CI: 11.67, 11.93) after pregnancy. Sulfonylurea utilization followed a surprisingly similar trend, as the pre-pregnancy baseline prevalence of $3.1 \%$ (CI: 3.08, 3.12) grew during pregnancy to $10.4 \%$ (CI: 10.34, 10.46) and then decreased to $2.5 \%$ (CI: $2.43,2.57$ ) after pregnancy.

In sub-group analysis of the type 2 diabetic women only, the pattern of anti-diabetic drug utilization was very similar to all diabetic women, except an expected lower prevalence of insulin use throughout each 3-month period. We noted an even lower rebound in utilization of metformin after pregnancy, with only $5.6 \%$ (CI: $5.51,5.69$ ) of type 2 diabetic women who used metformin post-delivery, but more than $12.4 \%$ (CI: $12.30,12.50)$ before pregnancy.

\section{Discussion}

We conducted a descriptive analysis on anti-diabetic drug utilization before, during and after pregnancy in diabetic women in order to guide future research on drug safety and effectiveness. Our study had several key findings. First, overall anti-diabetic drug utilization during pregnancy doubled over our ten-year study period. Second, despite this increase, we found a significant proportion of diabetic women with no drug treatment before, during and after pregnancy. Third, among the anti-diabetic drug classes we found interesting AD utilization pattern indicating changes in the treatment regimen during pregnancy. For example, the prevalence of metformin utilization decreased as pregnancy progressed from the 1 st to the 3rd trimester, but was re-established into the treatment regimen after pregnancy, although at less than half the prevalence of the before period. Insulin and sulfonylurea demonstrated a reversed pattern, as the overall prevalence of utilization in both drug classes increased over the course of pregnancy and then returned to a low prevalence after pregnancy similar to utilization before.

Current recommendations for the initial therapy of diabetes (both type 1 and type 2) emphasize pharmacological interventions [20]. According to the American Diabetes Association (ADA) and the European Association for the Study of Diabetes (EASD), the initial management of type 2 diabetes should use combination therapy of metformin and lifestyle changes with augmentation of therapy with additional oral anti-diabetic drug to maintain glycemic control [20]. Or initiate insulin at diagnosis for individuals who present with severe hyperglycemic symptoms [20]. The recommendation reflects a change in treatment approaches a decade ago, which suggested that early type 2 diabetes might be managed with diet and lifestyle modifications alone. This evolution in treatment paradigm may explain the increase in overall anti-diabetic drug utilization that we observed among diabetic women before, during, and after pregnancy over our study period.

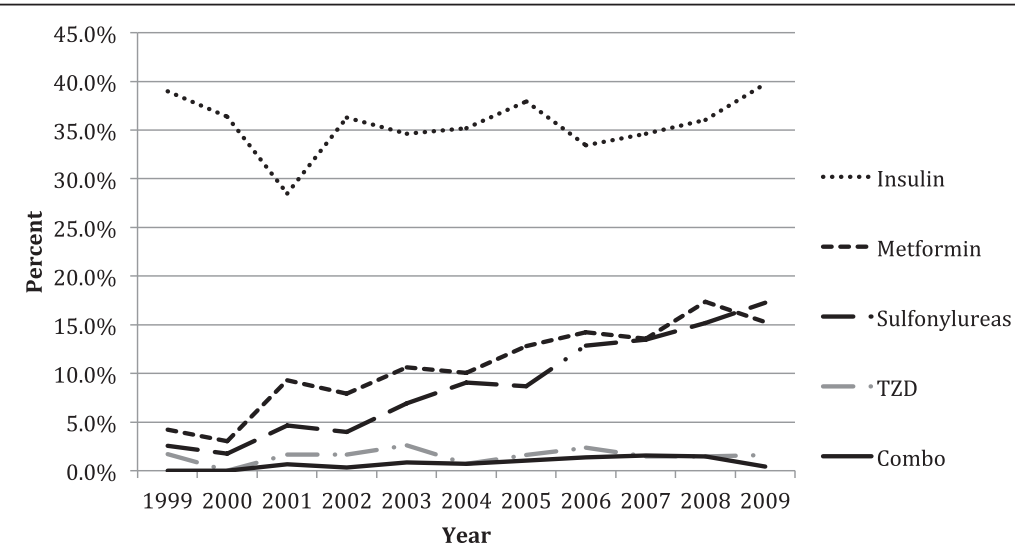

Figure 2 Annual prevalence of anti-diabetic drug utilization during pregnancy by drug class. 


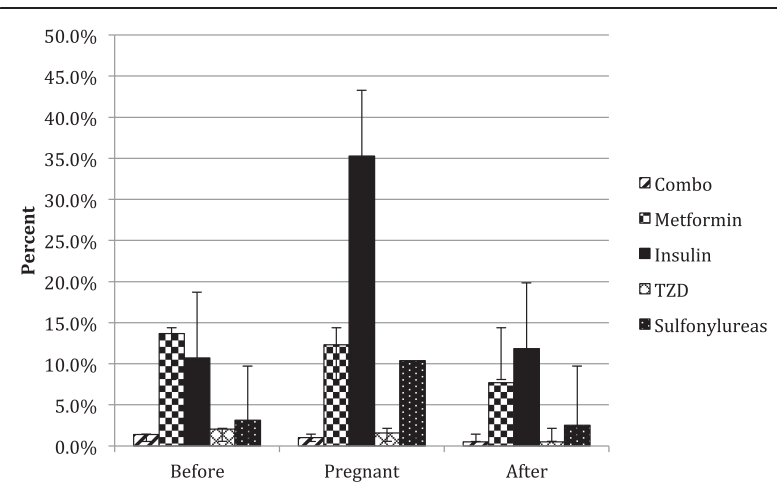

Figure 3 Pooled annual prevalence of anti-diabetic drug utilization, by drug class: before, during, and after pregnancy.

Interestingly, according to the National Health Interview Survey, for the past ten years the prevalence of diabetic adults who do not use insulin or oral anti-diabetic drugs to control their diabetes has slightly grown by $1 \%$ to more than $15 \%$ of US adults with diabetes [2,21]. The fact that we observed even higher proportions of non-treated patients in a managed care population with comprehensive drug benefits and increased medical attention due to pregnancy is surprising and raises questions about current treatment approaches. While the majority of pregnant woman may have had onset of type 2 diabetes in recent years and thus limited need for aggressive glycemic control, we still expected that current treatment guidelines and the emphasis on tight glucose control during pregnancy would have resulted in more comprehensive drug therapy. Unfortunately, because laboratory values are not available in claims data, it is unclear whether these women were able to achieve or maintain normoglycemia throughout pregnancy.

In general, the use of insulin to treat type 2 diabetes mellitus during pregnancy is accepted and recommended as safe and effective in achieving normal blood glucose levels [22,23]. There is also sufficient evidence to support that metformin is non-inferior to insulin with regards to neonatal safety, but comparative data regarding efficacy during pregnancy are lacking [24,25]. Furthermore, the majority of the metformin safety studies have been completed in women with polycystic ovarian syndrome or gestational diabetes, not in women with pre-existing diabetes, and have not evaluated pregnancy outcomes (pre-term labor, preeclampsia, cesarean section delivery) as safety endpoints $[24,26]$.

The distinct increase of sulfonylureas use during pregnancy observed in this cohort was noteworthy in this context, because this drug class is currently not recommended for this indication, including an FDA contraindication for use in the last 4 weeks of pregnancy. This notwithstanding, several studies have found no harmful effects and report good glycemic control with the use of sulfonylureas during pregnancy [27-30]. Again, the majority of studies on the use of this drug class in pregnancy address the use in gestational diabetic women and lack evidence on various aspects of safety and efficacy.

We conducted this study using administrative claims data. The IMS LifeLink database allowed us to investigate the prevalence of diabetes in pregnancy in a relatively large cohort of more than 96,000 pregnant women, sampled from over 100 commercial health plans across the US, with fully adjudicated medical and pharmaceutical claims. The study period, which spanned ten years, allowed for the examination of time trends in drug utilization of these women before, during and after pregnancy. Focus on a managed care setting allowed good observation of prescribing practices, because access to care is not a major limitation.

All administrative data have limitations and this study is no exception. Despite our large sample size, focus on women in private insurance is not representative of diabetes treatment pattern in the US. In addition, the selection of health plans in IMS may not be representative as suggested by the geographic distribution of diabetes prevalence that does not follow nationally reported data. However, comparisons across time and across trimesters are expected to be valid within the study cohort. By restricting the pregnancy cohort to only women with a prescription drug claim before pregnancy, we are omitting women without drug coverage and theoretically omitting women who are not receiving drug treatment or who are non-adherent to their medication regimen. We potentially underestimated drug use prevalence in instances where pharmacy claims were not submitted for reimbursement because patients paid cash for their prescriptions. However, since prescription copays should have provided cheaper alternatives to patients during the study period, we expect minimal misclassification. We limited this descriptive analysis to pregnant women with live births. Therefore, the drug utilization patterns that were seen within this descriptive analysis may be different from pre-existing diabetic women with unsuccessful pregnancies (i.e. miscarriage, stillbirth, or termination).

Finally, we aimed to focus our study on patients with type 2 diabetes, but had to accept limitations in the granularity of ICD9-CM codes used for billing. Studies have been largely unsuccessful in validating algorithms to distinguish between diabetes types [13-15,31]. In order to estimate the extent of potential misclassification we provide results of a sensitivity analysis using a conservative approach that did not allow any codes for type 1 or unspecified diabetes in our sub-cohort of type 2 diabetic patients. This approach was likely not sensitive and may have excluded patients differentially. 


\section{Conclusion}

Pre-existing diabetes is an increasing comorbidity in pregnant woman in the US. While the overall use of anti-diabetic medications during pregnancy increased, a larger than expected proportion of pregnant women did not have AD drug claims throughout the study period. Contrary to current recommendations, metformin use decreased as pregnancy progressed while sulfonylurea use increased. The high rate of oral anti-diabetic drug use during pregnancy emphasizes the need for conclusive evidence regarding safety and efficacy in terms of glucose control as well as maternal outcomes. Further research is needed in order to evaluate the safety of oral anti-diabetic agent use in pregnant women with pre-existing diabetes in terms of pregnancy and neonatal outcomes. Within this study, it we were unable to assess the impact of glycemic control and co-morbid conditions on the choice of antidiabetic agents throughout pregnancy. Therefore, it will also be important for future research to focus on the determinates of medication choices during pregnancy including the presence or on-set of co-morbid conditions and changes in glycemic control. Additionally, the lower prevalence of anti-diabetic drug utilization post-delivery indicates a possible need for further investigation.

\section{Competing interests}

The authors declare that they have no competing interests.

\section{Authors' contributions}

Conceived and designed the research: CK, JD, AW. Analyzed the data: CK. Wrote the paper: CK. Interpretation of data: CK, JD, AW. Critically revised manuscript: CK, JD, AW. All authors have approved the manuscript as submitted.

\section{Presentation of work}

The sub-group analysis of the type 2 diabetes data from this paper was presented at the 28th International Conference on Pharmacoepidemiology and Therapeutic Risk Management, in August 2012.

\section{Acknowledgements}

We received no funding in support of this research and this paper is not under review elsewhere. The American Foundation Pharmaceutical Education Fellowship and the Mary K Owens Fellowship supported CK. None of these entities had influence on the design and conduct of the study, collection, management, analysis, and interpretation of the data, and the preparation or approval of the manuscript.

\section{Author details}

${ }^{1}$ Department of Pharmaceutical Outcomes \& Policy, College of Pharmacy, Gainesville, FL, USA. ²Department of Epidemiology, University of Washington, Seattle, WA, USA. ${ }^{3}$ Colleges of Medicine and Public Health and Health Professions, University of Florida, Gainesville, FL, USA.

Received: 5 April 2013 Accepted: 23 December 2013 Published: 17 January 2014

\section{References}

1. Diagnosed and undiagnosed diabetes in the United States, all ages, 2010. [http://www.cdc.gov/diabetes/pubs/estimates11.htm\#1]

2. Cowie CC, Rust KF, Byrd-Holt DD, Eberhardt MS, Flegal KM, Engelgau MM, Saydah SH, Williams DE, Geiss LS, Gregg EW: Prevalence of diabetes and impaired fasting glucose in adults in the U.S. population: National Health And Nutrition Examination Survey 1999-2002. Diabetes Care 2006, 29(6):1263-1268.
3. Holing EV, Beyer CS, Brown ZA, Connell FA: Why don't women with diabetes plan their pregnancies? Diabetes Care 1998, 21(6):889-895.

4. Coustan DR: Pre-conception planning. The relationship's the thing. Diabetes Care 1998, 21(6):887-888.

5. Janz NK, Herman WH, Becker MP, Charron-Prochownik D, Shayna VL, Lesnick TG, Jacober SJ, Fachnie JD, Kruger DF, Sanfield JA: Diabetes and pregnancy. Factors associated with seeking pre-conception care. Diabetes Care 1995, 18(2):157-165.

6. Kitzmiller JL, Gavin LA, Gin GD, Jovanovic-Peterson L, Main EK, Zigrang WD: Preconception care of diabetes. Glycemic control prevents congenital anomalies. JAMA 1991, 265(6):731-736.

7. Bell R, Glinianaia SV, Tennant PW, Bilous RW, Rankin J: Peri-conception hyperglycaemia and nephropathy are associated with risk of congenital anomaly in women with pre-existing diabetes: a population-based cohort study. Diabetologia 2012, 55(4):936-947.

8. Schaefer-Graf UM, Buchanan TA, Xiang A, Songster G, Montoro M, Kjos SL: Patterns of congenital anomalies and relationship to initial maternal fasting glucose levels in pregnancies complicated by type 2 and gestational diabetes. Am J Obstet Gynecol 2000, 182(2):313-320.

9. Miller E, Hare JW, Cloherty JP, Dunn PJ, Gleason RE, Soeldner JS, Kitzmiller $J$ : Elevated maternal hemoglobin A1c in early pregnancy and major congenital anomalies in infants of diabetic mothers. N Engl J Med 1981, 304(22):1331-1334

10. Dunne F, Brydon P, Smith K, Gee H: Pregnancy in women with Type 2 diabetes: 12 years outcome data 1990-2002. Diabet Med 2003, 20(9):734-738.

11. Chen G, Khan N, Walker R, Quan H: Validating ICD coding algorithms for diabetes mellitus from administrative data. Diabetes Res Clin Pract 2010, 89(2):189-195.

12. Hebert PL, Geiss LS, Tierney EF, Engelgau MM, Yawn BP, McBean AM: Identifying persons with diabetes using Medicare claims data. Am J Med Qual 1999, 14(6):270-277.

13. Wei WQ, Leibson CL, Ransom JE, Kho AN, Caraballo PJ, Chai HS, Yawn BP, Pacheco JA, Chute CG: Impact of data fragmentation across healthcare centers on the accuracy of a high-throughput clinical phenotyping algorithm for specifying subjects with type 2 diabetes mellitus. J Am Med Inform Assoc 2012, 19(2):219-224

14. O'Malley KJ, Cook KF, Price MD, Wildes KR, Hurdle JF, Ashton CM: Measuring diagnoses: ICD code accuracy. Health Serv Res 2005, 40(5 Pt 2):1620-1639.

15. Zgibor JC, Orchard TJ, Saul M, Piatt G, Ruppert K, Stewart A, Siminerio LM: Developing and validating a diabetes database in a large health system. Diabetes Res Clin Pract 2007, 75(3):313-319.

16. Toh S, Mitchell AA, Werler MM, Hernández-Díaz S: Sensitivity and specificity of computerized algorithms to classify gestational periods in the absence of information on date of conception. Am J Epidemiol 2008, 167(6):633-640.

17. Andrade SE, Raebel MA, Morse AN, Davis RL, Chan KA, Finkelstein JA, Fortman KK, McPhillips H, Roblin D, Smith DH, et al: Use of prescription medications with a potential for fetal harm among pregnant women. Pharmacoepidemiol Drug Saf 2006, 15(8):546-554.

18. Hardy JR, Leaderer BP, Holford TR, Hall GC, Bracken MB: Safety of medications prescribed before and during early pregnancy in a cohort of 81,975 mothers from the UK general practice research database. Pharmacoepidemiol Drug Saf 2006, 15(8):555-564.

19. Margulis AV, Setoguchi S, Mittleman MA, Glynn RJ, Dormuth CR, HernándezDíaz S: Algorithms to estimate the beginning of pregnancy in administrative databases. Pharmacoepidemiol Drug Saf 2012, 22(1):16-24.

20. Association AD: Standards of medical care in diabetes-2011. Diabetes Care 2011, 34(Suppl 1):S11-61.

21. 2003 National Diabetes Fact Sheet. [http://www.cdc.gov/diabetes/pubs/ general.htm\#treatment]

22. Association AD: Standards of medical care in diabetes-2009. Diabetes Care 2009, 32(Suppl 1):S13-61.

23. Bulletins ACOP: ACOG practice bulletin. Clinical management guidelines for obstetrician-gynecologists. Number 60, march 2005. Pregestational diabetes mellitus. Obstet Gynecol 2005, 105(3):675-685.

24. Rowan JA, Hague WM, Gao W, Battin MR, Moore MP, Investigators MT: Metformin versus insulin for the treatment of gestational diabetes. N Engl J Med 2008, 358(19):2003-2015.

25. Group GD: Management of diabetes from preconception to the postnatal period: summary of NICE guidance. BMJ 2008, 336(7646):714-717. 
26. Glueck CJ, Wang P, Goldenberg N, Sieve-Smith L: Pregnancy outcomes among women with polycystic ovary syndrome treated with metformin. Hum Reprod 2002, 17(11):2858-2864.

27. Langer O, Conway DL, Berkus MD, Xenakis EM, Gonzales O: A comparison of glyburide and insulin in women with gestational diabetes mellitus. N Engl J Med 2000, 343(16):1134-1138.

28. Jacobson GF, Ramos GA, Ching JY, Kirby RS, Ferrara A, Field DR: Comparison of glyburide and insulin for the management of gestational diabetes in a large managed care organization. Am J Obstet Gynecol 2005, 193(1):118-124.

29. Koren G: Glyburide and fetal safety; transplacental pharmacokinetic considerations. Reprod Toxicol 2001, 15(3):227-229.

30. Carpenter MW, Coustan DR: Criteria for screening tests for gestational diabetes. Am J Obstet Gynecol 1982, 144(7):768-773.

31. Kho AN, Hayes MG, Rasmussen-Torvik L, Pacheco JA, Thompson WK Armstrong LL, Denny JC, Peissig PL, Miller AW, Wei WQ, et al: Use of diverse electronic medical record systems to identify genetic risk for type 2 diabetes within a genome-wide association study. J Am Med Inform Assoc 2012, 19(2):212-218.

doi:10.1186/1471-2393-14-28

Cite this article as: Knox et al: Anti-diabetic drug utilization of pregnant diabetic women in us managed care. BMC Pregnancy and Childbirth 2014 14:28

\section{Submit your next manuscript to BioMed Central and take full advantage of:}

- Convenient online submission

- Thorough peer review

- No space constraints or color figure charges

- Immediate publication on acceptance

- Inclusion in PubMed, CAS, Scopus and Google Scholar

- Research which is freely available for redistribution 